\title{
Clinical significance in COPD patients followed in a real practice
}

\author{
Júlio César Mendes de Oliveira ${ }^{1,2}$, Isabella de Carvalho Aguiar², Ana Carolina Negrinho de Oliveira Beloto ${ }^{1,2}$, \\ Israel Reis Santos ${ }^{2}$, Fernando Sergio Studart Leitão Filho ${ }^{3}$, Luciana M Malosa Sampaio², Claudio F Donner ${ }^{4}$ \\ and Luís Vicente Franco de Oliveira ${ }^{2 *}$
}

\begin{abstract}
Background: Chronic obstructive pulmonary disease (COPD) is an important public health issue in many countries which is estimated to become the fifth cause of disability and the third cause of mortality in the world within 2020. The objective of this study was to identify the clinical characteristics in the real clinical practice of a sample of patients with COPD followed in a pulmonology clinic.

Methods: The initial sample contained 207 subjects with respiratory claims that searched for specialized treatment and initiated regular monitoring between 2004 and 2009 in a private clinic localized in Cascavel, in the state of Parana, Brazil. Demographic data (weight, height, body mass index - BMI), history of comorbidities, use of respiratory and non respiratory drugs were also registered.

Results: The main cause related to the development of COPD was current or prior smoking (92.0\%); the most frequently reported symptom was dyspnea (95.0\%), followed by cough (86.1\%), wheezing (69.4\%) and sputum production (40.0\%). During the follow up, 51 patients developed the need for oxygen therapy (28.3\%). In 96 patients, there were periods of acute exacerbation, resulting in 37 hospitalizations. In addition to COPD, a significant number of comorbidities were identified, being cardiovascular disease and neurological disorders the most prevalent ones.

Conclusions: Based on the data collected, we could outline the profile of patients with COPD, showing characteristics of an elderly population, with multiple comorbidities, suggesting a health related quality of life lower than expected.
\end{abstract}

Keywords: COPD, Dyspnea, Smoking

\section{Background}

Chronic obstructive pulmonary disease (COPD) is an important public health issue in many countries which is estimated to become the fifth cause of disability and the third cause of mortality in the world within 2020 [1,2].

The prevalence of COPD in the world's population is considered to be around 1\% concerning all age groups, rising to $8-10 \%$ or more in individuals $\geq 40$ years old $[3,4]$. In Brazil, the PLATINO study (Latin American Project for the Investigation of Pulmonary Obstruction) identified a COPD prevalence of $15.8 \%$ in the population

\footnotetext{
* Correspondence: oliveira.Ivf@uninove.br

${ }^{2}$ Rehabilitation Sciences Master and Doctoral Degree Program - Nove de Julho University, UNINOVE, Sao Paulo, SP, Brazil

Full list of author information is available at the end of the article
}

living in the metropolitan region of São Paulo, while another epidemiological study demonstrated that the prevalence of COPD is $9.1 \%$ when considering the population between 40 and 70 years old [6].

Few studies have provided data about the epidemiology of COPD [5,7-9] in the Latin America. Exposition to respiratory risk factors also differ from one geographical area to another [10] and these factors, associated to genetic predisposition and smoking, may be the reason for the different features and severities of COPD patients among the countries [11]. In recent years, epidemiological studies have demonstrated a high and rising cost of COPD around the world [3,4]. Moreover, the adherence to treatment guidelines is low, especially in the less developed countries [12-15].

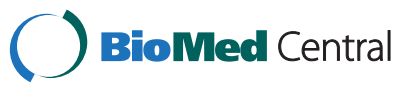


COPD patients followed up in outpatients clinics are usually elderly and have, along with the respiratory disease, many other comorbidities [16,17]. There are thousands of articles in the literature devoted specifically to patients with COPD, however, as any clinical study has specific inclusion and exclusion criteria, the current researches are restricted to subgroups of COPD patients, making a substantial number of other patients ineligible primarily because of their comorbidities. In this way, it is increasingly more difficult to delineate the true profile of COPD patients in outpatient settings [10]. This paper aims at characterizing these patients from the assessment of demographic, clinical, and spirometric variables.

\section{Methods}

In this cross-sectional study, the initial sample was composed of 207 subjects with respiratory complaints who looked for specialized pneumological care and started a regular follow up between 2004 and 2009 in a private clinic in Cascavel, in province of Parana, Brazil.

The diagnosis of COPD was confirmed by compatible clinical presentation, presence of known risk factors as smoking or exposition to biomass combustion (especially that from burned-over land) and observation of post-bronchodilator $\mathrm{FEV}_{1} / \mathrm{FVC}$ ratio $<0.70$ at spirometry, according to Global Initiative for Chronic Obstructive Lung Disease (GOLD) guidelines [2,16,17].

During the evaluation visit, all patients underwent detailed anamnesis and physical examination, both conducted by a pneumologist. It was investigated: the patient's main symptoms; degree of basal dyspnea according to the modified Medical Research Council scale (mMRC) [18]; causes related to COPD development (smoking or exposition to biomass combustion); previous or current tobacco consumption; measurement of tobacco exposure in pack/years; previous number of hospitalization events and exacerbations; current use of long-term oxygen therapy (LTOT); search for non-respiratory comorbidities and description of all respiratory and non-respiratory medications currently in use.

In the same day of clinical evaluation, study subjects' weight and height were measured. These subjects underwent pre and post-bronchodilator spirometry, following administration of albuterol $400 \mu \mathrm{g}$ via MDI device, according to the American Thoracic Society (ATS) guidelines for lung function [19]. Patients were previously informed by phone to discontinue bronchodilator use before spirometric evaluation, so that short or long acting $\beta_{2}$-agonists and tiotropium were withheld for at least 6,12 and $24 \mathrm{~h}$, respectively.

There was no restriction on the number or type of inhaled or oral medications prescribed by the pneumologist for controlling respiratory symptoms; they varied according to clinical and spirometric data, as well as each patient's income.

This study was approved by the Committee of Ethics and Research of UniversidadeNove de Julho (UNINOVEBrazil) under Protocol 219561/2008. All patients signed Informed Consent prior to participation and had the option to withdraw from the study at any time.

\section{Statistical analysis}

The data are presented in a descriptive mode. The variables, when indicated, are presented in absolute numbers, average, and standard deviation or as percentages.

\section{Results}

Our sample involved 180 patients with respiratory complaints, with an average age of $67.7 \pm 10.1$ years. There was an absolute prevalence of male gender (79\%). The main cause related to COPD development was previous or current tobacco consumption (92\%), including 9 cases probably related to passive tobacco smoke exposure (5\%). The average tobacco smoke exposure was $51 \pm$ 14.9 pack/years. Another less frequent cause was the exposure to biomass combustion (wood-fired ovens and burned-over land), identified in 17 patients (9.4\%). The average body-mass index (BMI) was $24.9 \pm 5.2 \mathrm{~kg} / \mathrm{m}^{2}$ with 45 patients $(25 \%)$ presenting a BMI $\geq 21 \mathrm{~kg} / \mathrm{m}^{2}$ (Table 1).

The most frequently reported symptom was dyspnea (95\%) and $72.4 \%$ of the patients referred to dyspnea degree 3 or 4 according to the mMRC scale. The other symptoms, sorted in decreasing frequency order, were chronic cough (86.1\%), wheezing (69.4\%), and sputum production (40\%). The average post-bronchodilator $\mathrm{FEV}_{1}$ was $44.8 \pm 16.7 \%$ of predicted, with most patients being classified into GOLD III (36.7\%) and IV (20.5\%) stages. During the follow up, 51 patients evolved with need for LTOT (28.3\%); among these patients in 13 cases (25\%), after the optimization of bronchodilator treatment, there was discontinuation of oxygen supplementation. Acute periods of exacerbation occurred in 96 subjects (53.3\%), eventually amounting to 119 episodes

\section{Table 1 Baseline demographics of study population} ( $\mathrm{n}=\mathbf{1 8 0})$

\begin{tabular}{ll}
\hline Variables & Values \\
\hline Age, years & $67.7 \pm 10.1$ \\
\hline Sex (M:F), N (\%) & $142(79 \%) / 38(21 \%)$ \\
\hline Weight, $\mathrm{Kg}$ & $69.1 \pm 16.4$ \\
\hline BMI, kg/m ${ }^{2}$ & $24.9 \pm 5.2$ \\
\hline Smokers (current and former), N (\%) & $166(92.0 \%)$ \\
\hline Smoking, pack/years & $51 \pm 14.9$ \\
\hline Biomass exposure, N (\%) & $17(9.4 \%)$ \\
\hline
\end{tabular}

Data are expressed as means \pm SD unless otherwise indicated. 
and resulting in 37 hospitalizations. Table 2 describes the main clinical features of the evaluated patients.

Evaluating the clinical history of follow up cases, we identified, along with COPD, a significant number of comorbidities, being the most prevalent the cardiovascular and neurological diseases, observed, respectively, in $58 \%$ and $21 \%$ of the subjects (Figure 1). Hypertension was the most common cardiovascular comorbidity, identified in 100 patients (55\%). In 79 patients (43.9\%) only a non-respiratory comorbidity was diagnosed, while 39 patients $(21.7 \%)$ had two comorbidities and 12 cases $(6.7 \%)$ presented three or more comorbidities. In face of it, 90 patients (43.4\%) reported daily use of three medications (including the respiratory ones), while 70 (33.8\%) use four medications and $47(22.8 \%)$ use five or more medications. Table 3 displays the main classes of respiratory and non-respiratory medications used by the participants in the sample.

In our study, the symptoms of COPD were more frequently ameliorated by prescription of long-acting $\beta_{2}$-agonists (formoterol or salmeterol) combined to inhaled corticosteroids (90\%) as a maintenance treatment. The tiotropium was prescribed to $31.7 \%$ of the patients, especially in case of persistence of symptoms among patients already taking other classes of bronchodilators. As relief medication, the most used drugs were short-acting $\beta_{2}$-agonists (albuterol or fenoterol) (88.9\%). Another interesting fact of our study concerned the analysis of

\section{Table 2 Clinical and functional characteristics of} evaluated COPD patients $(n=180)$

\begin{tabular}{|c|c|}
\hline Dyspnea & $171(95 \%)$ \\
\hline Dyspnea Degree 1 (mMRC) & $16(8.8 \%)$ \\
\hline Dyspnea Degree 2 (mMRC) & $25(13.8 \%)$ \\
\hline Dyspnea Degree 3 (mMRC) & $92(51.1 \%)$ \\
\hline Dyspnea Degree 4 (mMRC) & $38(21.3 \%)$ \\
\hline Chronic Cough & $155(86.1 \%)$ \\
\hline Sputum Production & $72(40.0 \%)$ \\
\hline Wheezing & 125 (69.4\%) \\
\hline Post-bronchodilator Spirometry: & Mean \pm SD \\
\hline FVC (L) & $2.19 \pm 0.99$ \\
\hline FVC (\% of predicted) & $75.0 \pm 15.0$ \\
\hline $\mathrm{FEV}_{1}(\mathrm{~L})$ & $1.17 \pm 0.52$ \\
\hline $\mathrm{FEV}_{1}(\%$ of predicted $)$ & $44.81 \pm 16.7$ \\
\hline $\mathrm{FEV}_{1} / \mathrm{FVC}(\%)$ & $57 \pm 12$ \\
\hline COPD stage: & $\underline{\mathrm{N}(\%)}$ \\
\hline GOLD I & $14(7.8 \%)$ \\
\hline GOLD II & $63(35.0 \%)$ \\
\hline GOLD III & $66(36.7 \%)$ \\
\hline OLD IV & $37(20.5 \%)$ \\
\hline
\end{tabular}

Data are expressed as number (\%) or means \pm SD as appropriate. non-respiratory medications, with $86.1 \%$ of patients taking regularly antihypertensives and diuretics (86.1\%), for example. Table 3 displays the main respiratory and non-respiratory medications regularly used in the studied sample.

There was no difference in the frequency of exacerbations, use of LTOT and comorbidities according to gender. However, we observed a higher frequency of comorbidities in patients $>60$ years old in comparison to patients $\leq 60$ years, and this finding achieved statistical significance $(\mathrm{p}=0.04)$.

\section{Discussion}

The profile of COPD patients of our study revealed that they are: elderly, mainly men, usually in advanced stages of the disease and presenting multiple comorbidities. Smoking was related by $92 \%$ of patients, being probably the most common factor associated with COPD development in this study, what is in accordance to the available literature [2,5].

Higher age is compatible with the period between the beginning of exposure (usually tobacco smoke) and the development of COPD, as less aged patients reflect probably a higher genetic predisposition or even deficiency of $\alpha 1$-antitrypsin [2,20]. The prevalence of male gender is consistent with previous studies in literature, with one study indicating the presence of $83 \%$ male individuals among more than 10,000 patients followed up in a respiratory clinic in Spain $[17,21]$. This finding probably reflects the higher prevalence of tobacco smoking and a higher exposure to occupational activities such as biomass combustion in male gender, which could explain the higher incidence of COPD among men [10,22,23]. Because of higher age, the presence of other non-respiratory comorbidities is more common in COPD patients; in our sample we observed that $72.2 \%$ of the subjects had at least one non-respiratory comorbidity, with cardiovascular diseases (coronary insufficiency, heart failure and arrhythmia) being the most prevalent ones. In the multicentric EPOCA (Enfermedad Pulmonar Obstructiva Crónica en Acción) Project, which was also dedicated to the analysis of the features of patients with COPD, the prevalence of comorbidities varied considerably according to the evaluated country, oscillating from $38.1 \%$ in Argentina to $63.4 \%$ in Spain [17].

The main symptom reported by the population studied was dyspnea (92\%), reflex of the ventilatory limitation observed in COPD. The EPOCA study found similar results, with dyspnea being reported by $97 \%$ of the patients, followed by chronic cough (79.6\%) and sputum production (70.5\%) [17]. COPD stages II and III were the most prevalent $(71.7 \%)$; this probably may be explained by delayed diagnosis (sub-diagnosis) at the earlier stages, since many patients initially ascribe their 


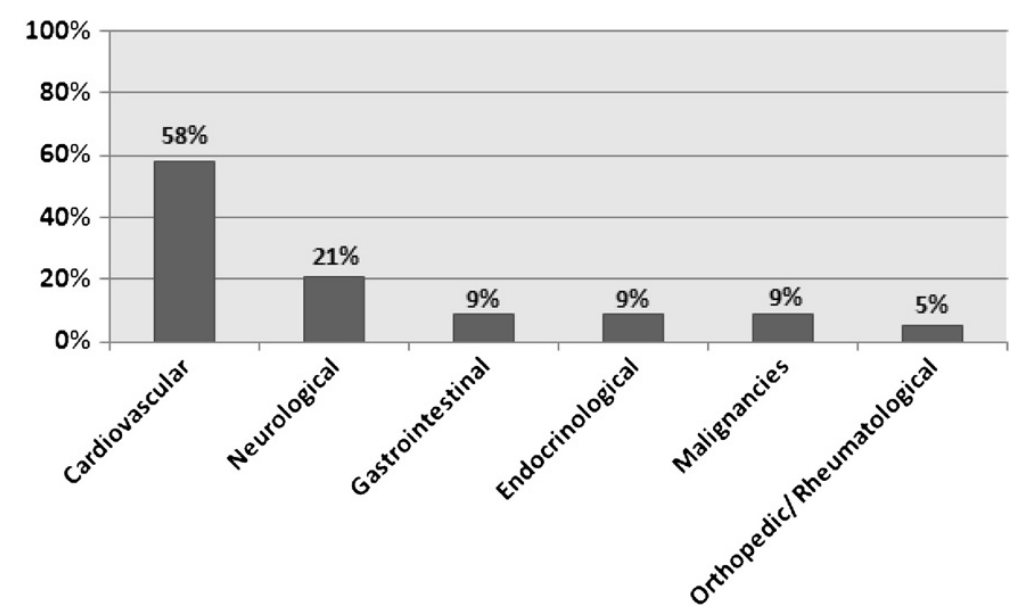

Figure 1 Comorbidities found in evaluated COPD patients.

effort intolerance, due to COPD, to aging and sedentarism. The PLATINO study identified that $85.7 \%$ of the 144 patients diagnosed with COPD in the metropolitan region of Sao Paulo had never received this diagnosis in their lives [24]. Moreover, the same study observed that, among the patients previously diagnosed with COPD, $42.7 \%$ had never been counseled to stop smoking and $82.3 \%$ were not receiving the recommended pharmacologic treatment.

Regarding the use of medications for the respiratory system, it is interesting to note that almost $60 \%$ of the sample consisted of patients with stage III and IV of the GOLD classification. Based on this finding, the high prescription in our sample of patients of $\beta_{2}$-agonists associated with long-term inhaled corticosteroids (97.8\%) and tiotropium (31.7\%) is easily explicable.

Similarly, also the great use of methylxanthines among patients $(85 \%)$ can be explained. The GOLD guidelines point out that inhaled bronchodilators, where available, should be used as first-line treatment in COPD, rather than oral bronchodilators, including methylxanthines. However, the same guidelines emphasize that methylxanthines can and should be considered in the treatment of patients with COPD who remain symptomatic despite the use of inhaled bronchodilators such as long-acting $\beta_{2}$-agonists association and tiotropium. Furthermore, methylxanthines are low cost medications in Brazil, compared to some classes of inhaled bronchodilators, which may have contributed to the prescription above expectations, according to recommendations from international guidelines.

The presence of LTOT in our sample is consistent with previous studies, which reported that around 25\% of the followed subjects with COPD use LTOT $[13,21,25]$. The high frequency of LTOT among these patients is justified by the loss in lung function and the ventilation/perfusion mismatch, especially in the most advanced phases of COPD [2,13].

We observed that almost one-third of the patients use digitalic drugs daily; this is probably related to left ventricle systolic dysfunction (LVSD) or even right failure due to corpulmonale. A recent systematic review revealed that the connection between COPD and LVSD is probably much more prevalent than previously estimated; superimposition rates between these two diseases varied from $10 \%$ to $46 \%$, especially during periods of

Table 3 Use of respiratory and non-respiratory medications among evaluated COPD patients $(n=180)$

\begin{tabular}{ll}
\hline Non-respiratory medications & $\mathrm{N}(\%)$ \\
\hline Antihypertensivesincluding diuretics & $155(86.1 \%)$ \\
\hline Antidiabetics & $26(14.5 \%)$ \\
\hline Platelet antiaggregants & $37(20.5 \%)$ \\
\hline Antidepressants & $30(16.6 \%)$ \\
\hline Analgesics & $7(3.8 \%)$ \\
\hline Digitalics & $52(28.8 \%)$ \\
\hline Prokinetics & $17(9.4 \%)$ \\
\hline Arterial vasodilators & $32(17.7 \%)$ \\
\hline Antiarrhythmics & $35(19.4 \%)$ \\
\hline Hypolipidemic drugs & $39(21.6 \%)$ \\
\hline Respiratory medications & $\mathrm{N} \mathrm{( \% )}$ \\
\hline \hline Short-acting $\beta_{2}$-agonists/lpratropium & $160(88.9 \%)$ \\
\hline Long-acting $\beta_{2}$-agonists & $14(7.8 \%)$ \\
\hline Long-acting $\beta_{2}$-agonists plus inhaled & $162(90 \%)$ \\
corticosteroids & \\
\hline Tiotropium & $57(31.7 \%)$ \\
\hline Inhaled corticosteroids & $5(2.8 \%)$ \\
\hline Methilxantines & $153(85 \%)$ \\
\hline
\end{tabular}


COPD exacerbation [26]. In our sample, corpulmonale was identified in 30 patients $(16.6 \%)$, whereas the presence of LVSD was suggested in 20 patients (11.1\%), according to echocardiographic findings.

We also point out the high incidence of systemic arterial hypertension (55\%) in the evaluated subjects (average age 67.7 years), since the prevalence of this comorbidity (55\%) increases linearly with age $[26,27]$. Besides that, many patients were using diuretics specifically to ameliorate edema due to corpulmonale, or angiotensin-converting enzyme (ACE) inhibitors due to LSVD, thus explaining the use of antihypertensives (including diuretics) in 155 patients (86.1\%).

It is important to emphasize that almost $20 \%$ of the patients took regularly antidepressants, a possible direct reflex of patients' compromised health status and quality of life [23]. In this context, it is interesting to quote a recent case-control study with more than 35,000 patients with COPD which identified that the existence of COPD itself doubles the risk of depression (OR 2.01, IC95\% 1.45-2.78) [28]. Another finding of concern in our study is the fact that the evaluated patients took many different types of drugs, an average of at least four medications a day. This is clinically relevant, since COPD patients are usually elderly patients, who frequently experience visual, hearing, and even cognitive deficits, which could possibly reduce their compliance to these medications, especially when they are not adequately assisted by their relatives [29].

\section{Conclusion}

In conclusion, we observed that COPD patients followed up are usually elderly, mainly men, and have multiple comorbidities, especially cardiovascular diseases. Therefore, a good design of the clinical profile of patients with COPD may probably result in a more effective and individualized therapeutic approach. As limitation of our study we can quote the fact we did not evaluate the impact of respiratory and non-respiratory comorbidities in the quality of life, as well as the compliance to medications in use.

\section{Competing interests}

The authors declare that there is no association with any commercial enterprise that has interest in the object of this study.

\section{Author details}

${ }^{1}$ Institute of the Lung, Cascavel, PR, Brazil. ${ }^{2}$ Rehabilitation Sciences Master and Doctoral Degree Program - Nove de Julho University, UNINOVE, Sao Paulo, SP, Brazil. ${ }^{3}$ Respiratory Division of Medicine School, Fortaleza University, UNIFOR, Fortaleza, CE, Brazil. ${ }^{4}$ Mondo Medico, Multidisciplinary and Rehabilitation Outpatient Clinic, Borgomanero, No, Italy.

Received: 10 October 2012 Accepted: 29 March 2013

Published: 28 June 2013

\section{References}

1. Jemal A, Ward E, Hao YA, Thun M: Trends in the leading causes of death in the United States, 1970-2002. JAMA 2005, 294(10):1255-1259.
2. Global Initiative for Chronic Obstructive Lung Disease: Global strategy for the diagnosis, management and prevention of chronic obstructive pulmonary disease. Bethesda: NHLBI/WHO workshop report; 2008. [updated 2013; cited 2013 03/21/2013]; Available from: www.goldcopd.com.

3. Chapman KR, Mannino DM, Soriano JB, Vermeine PA, Buist AS, Thun MJ, Connell C, Jemal A, Lee TA, Miravitlles M, Aldington S, Beasley R: Epidemiology and costs of chronic obstructive pulmonary disease. Eur Respir J 2006, 27:188-207.

4. Halbert RJ, Natoli JL, Gano A, Badamgarav E, Buist AS, Mannino DM: Global burden of COPD: systematic review and meta-analysis. Eur Respir J 2006, 28:523-532.

5. Menezes AM, Lopez MV, Hallal PC, Muino A, Perez-Padilla R, Jardim JR, Valdivia G, Pertuzé J, de Oca MM, Tálamo C, Victora CG, PLATINO Team: Prevalence of smoking and incidence of initiation in the Latin American adult population: the PLATINO study. BMC Public Health 2009, 9:151.

6. Peña VS, Miravitlles M, Gabriel R, Jiménez-Ruiz CA, Villasante C, Masa JF, Viejo JL, Fernández-Fau L: Geographical variations in prevalence and underdiagnosis of COPD: results of the IBERPOC multicentre epidemiological study. Chest 2000, 118:981-989.

7. Kim DS, Kim YS, Jung K-S, Chang JH, Lim CM, Lee JH, Uh ST, Shim JJ, Lew WJ, Korean Academy of Tuberculosis and Respiratory Diseases: revalence of chronic obstructive pulmonary disease in Korea: a population-based spirometry survey. Am J Respir Crit Care Med 2005, 172:842-847.

8. Wang Y-C, Lin J-M, Li C-Y, Lee LT, Guo YL, Sung FC: Prevalence and risks of chronic airway obstruction. A population cohort study. Chest 2007, 131:705-710.

9. Fukuchi $Y$, Nishimura M, Ichinose M, Adachi M, Nagai A, Kuriyama T, Takahashi K, Nishimura K, Ishioka S, Aizawa H, Zaher C: COPD in Japan: the Nippon COPD Epidemiology study. Respirology 2004, 9:458-465.

10. Menezes AM, Perez-Padilla R, Jardim JRB, Muiño A, Lopez MV, Valdivia G, Montes de Oca M, Talamo C, Hallal PC, Victora CG, PLATINO Team: Chronic obstructive pulmonary disease in five Latin American cities (the PLATINO study): a prevalence study. Lancet 2005, 366:1875-1881.

11. Buist AS, McBurnie MA, Vollmer WM, William M, Gillespie S, Burney P, Mannino DM, Menezes AM, Sullivan SD, Lee TA, Weiss KB, Jensen RL, Marks GB, Gulsvik A, Nizankowska-Mogilnicka E, BOLD Collaborative Research Group: International variation in the prevalence of COPD (the BOLD study): a population-based prevalence study. Lancet 2007, 370:741-750.

12. De Miguel J, Izquierdo Alonso JL, Rodríguez G-M, de Lucas Ramos P, Molina Paris J: Tratamiento farmacológico de la EPOC en dos niveles asistenciales. Grado de adecuación a las normativas recomendadas. Arch Bronconeumol 2003, 39:195-202.

13. Miravitlles M, Ferrer M, Pont A, Viejo JL, Masa JF, Gabriel R, Jiménez-Ruiz CA, Villasante C, Fernández-Fau L, Sobradillo V: Characteristics of a population of COPD patients identified from a population-based study. Focus on previous diagnosis and never smokers. Respir Med 2005, 99:985-995.

14. Rennard S, Decramer M, Calverley PM, Pride NB, Soriano JB, Vermeine PA, Vestbo J: Impact of COPD in North America and Europe in 2000: subjects' perspective of Confronting COPD International Survey. Eur Respir J 2002, 20:799-805.

15. Roche N, Lepage T, Bourcereau J, Terrioux P: Guidelines versus clinical practice in the treatment of chronic obstructive pulmonary disease. Eur Respir J 2001, 18:903-908.

16. Jardim JR, de Oliveira JC, Nascimento O: II Consenso Brasileiro sobreDoençaPulmonarObstrutivaCrônica - DPOC. J Bras Pneumol 2004, 30(S. 5):9-41.

17. Miravitlles M, Murio C, Tirado-Conde G, Levy G, Muellerova H, Soriano JB, Ramirez-Venegas A, Ko FW, Canelos-Estrella B, Giugno E, Bergna M, Chérrez I, Anzueto A: Geographic differences in clinical characteristics and management of COPD: the EPOCA study. Int J Chron Obstruct Pulmon Dis 2008, 3(4):803-814.

18. Bestall JC, Paul EA, Garrod R, Garnham R, Jones PW, Wedzicha JA: Usefulness of the medical research council (MRC) dyspnoea scale as a measure of disability in patients with chronic obstructive pulmonary disease. Thorax 1999, 54(7):581-586.

19. Miller MR, Hankinson J, Brusasco V, Burgos F, Casaburi R, Coates A, Crapo R, Enright $P$, van der Grinten CP, Gustafsson P, Jensen R, Johnson DC, MacIntyre N, McKay R, Navajas D, Pedersen OF, Pellegrino R, Viegi G, Wanger J, ATS/ERS Task Force: Standardisation of spirometry. Eur Respir J 2005, 26(2):319-338.

20. Esteban C, Moraza J, Quintana JM, Aburto M, Capelastegui A: Use of medication and quality of life among patients with COPD. Respir Med 2006, 100:487-495. 
21. Viejo-Banuelos JL, Pueyo-Bastida A, Fueyo-Rodriguez A: Characteristics of outpatients with COPD in daily practice: The E4 Spanish project. Respir Med 2006, 100(12):2137-2143.

22. Monteiro CA, Cavalcante TM, Moura EC, Claro RM, Szwarcwald CL: Population-based evidence of a strong decline in the prevalence of smokers in Brazil (1989-2003). Bull World Health Organ 2007, 85(7):527-534.

23. Santos SR, Goncalves MS, LeitaoFilho FS, Jardim JR: Profile of smokers seeking a smoking cessation program. J Bras Pneumol 2008, 34(9):695-701.

24. Nascimento OA, Camelier A, Rosa FW, Menezes AM, Perez-Padilla R, Jardim JR: Chronic obstructive pulmonary disease is underdiagnosed and undertreated in São Paulo (Brazil): results of the PLATINO study. Braz J Med Biol Res 2007, 40(7):887-895.

25. Herland K, Akselsen JP, Skjonsberg OH, Bjermer L: How representative are clinical study patients with asthma or COPD for a larger "real life" population of patients with obstructive lung disease? Respir Med 2005, 99(1):11-19.

26. Horvathova H, Kimlikova K, Balazovjech I, Kyselovic I: Compliance and the therapeutic effect in patients with arterial hypertension. Bratis/LekListy 2003, 104(4-5):149-154.

27. Rutten FH, Cramer MJ, Lammers JW, Grobbee DE, Hoes AW: Heart failure and chronic obstructive pulmonary disease: An ignored combination? Eur J Heart Fail 2006, 8(7):706-711.

28. Schneider C, Jick SS, Bothner U, Meier CR: Chronic obstructive pulmonary disease and the risk of depression. Chest 2010, 137(2):341-347.

29. Rubinstein AL, Irazola VE, Bazanno LA, Sobrino E, Calandrelli M, Lanas F, Lee AG, Manfredi JA, Olivera H, Ponzo J, Seron P, He J: Detection and follow-up of chronic obstructive pulmonary disease (COPD) and risk factors in the Southern Cone of Latin America: the pulmonary risk in South America (PRISA) study. BMC Pulm Med 2011, 11(34):1471-1476.

doi:10.1186/2049-6958-8-43

Cite this article as: de Oliveira et al: Clinical significance in COPD

patients followed in a real practice. Multidisciplinary Respiratory Medicine 2013 8:43.

\section{Submit your next manuscript to BioMed Central and take full advantage of:}

- Convenient online submission

- Thorough peer review

- No space constraints or color figure charges

- Immediate publication on acceptance

- Inclusion in PubMed, CAS, Scopus and Google Scholar

- Research which is freely available for redistribution 